\title{
Translational research in retinology
}

This article was published in the following Dove Press journal:

Clinical Ophthalmology

13 October 201 |

Number of times this article has been viewed

\author{
Rubens Camargo Siqueira ${ }^{1,2}$ \\ Rodrigo Jorge ${ }^{2}$ \\ 'Rubens Siqueira Research Center, \\ São José do Rio Preto, São Paulo, \\ Brazil; ${ }^{2}$ Retina and Vitreous Section, \\ Department of Ophthalmology, \\ School of Medicine of Ribeirão Preto, \\ University of São Paulo, Brazil
}

Correspondence: Rubens Camargo Siqueira

Rua Saldanha Marinho 28I5-sala 42, São José do Rio Preto/SP Brazil, CEP: I50I0-100

Tel +55 1732345858

Email rubenssiqueira@terra.com.br
Abstract: Clinical laboratories are strong, integral partners in personalized health care. Laboratory databases hold a vast amount of data on human phenotypes, genotypes, biomarkers, progression of disease, and response to therapy. These structured and unstructured free text data are critical for patient care and a resource for personalized medicine and translational research. Laboratory data are integrated into many electronic medical records that provide "summary reports" and "trending" to visualize longitudinal patient data. Recent advances in ophthalmology such as gene therapy, cell therapy using stem cells, and also retinal prosthesis explore the potential of translational research marking a new era in research into the diagnosis and treatment of eye diseases.

Keywords: translational, retinal diseases, stem cell, gene therapy

\section{Introduction}

Scientific research is traditionally divided into two categories: basic research and applied research. Basic research is needed to provide a better understanding of normal conditions vs disease, but it does not directly translate that knowledge into useful clinical applications. Translational research is the advancement of science applied to the development of new diagnostic tests, drugs and/or intervention techniques for patients with an established understanding of their disease development and progression.

The main goal of translational research is to integrate advances in biotechnology in clinical trials, that is, furthering research from the bench to the bedside (Figure 1).

The observations of clinical investigators on the nature and progression of diseases direct basic scientific research. Researchers use clinical samples to study the diagnosis, the expression of biomarkers, differences between normal and disease conditions, and responses to therapy. Basic scientists then provide to clinicians new treatment strategies based on laboratory data. This constant feedback assists in the discovery of disease biomarkers and drug targets, resulting in a more rational development of medications and improves the effectiveness of therapeutic agents.

Translational research also enables faster development of potential therapies, reducing the time between the identification of drug targets and the availability of clinically relevant treatment options. Currently, the completion of all phases of preclinical testing and clinical trials of a single drug takes 7-12 years, but the great amount of translational research being conducted around the world is a promising sign for faster progress in the near future. ${ }^{1}$ 


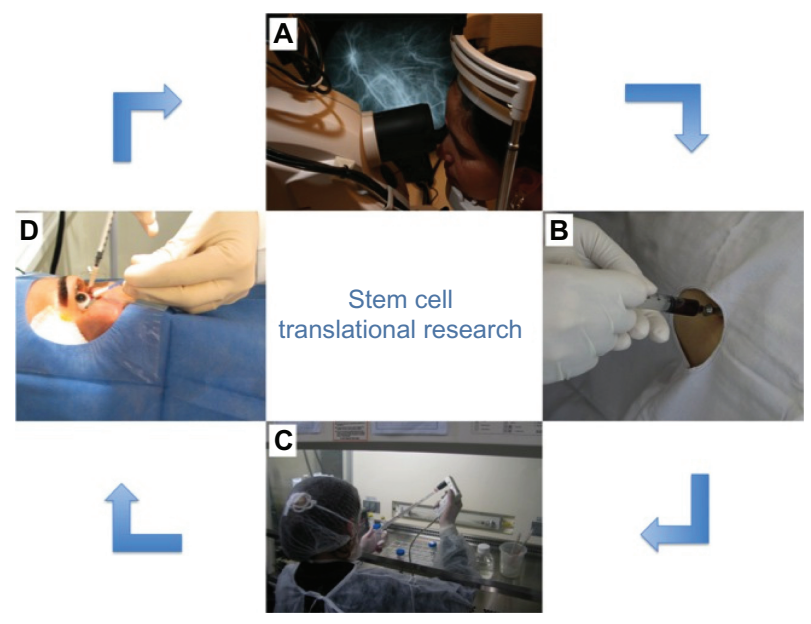

Figure I Scheme showing translational research conducted by our research group (Clinicaltrial.gov: NCT0106856I). This clinical trial was about the use of bone marrow-derived stem cell for the treatment of retinal dystrophy. The patient is examined at the research center $(\mathbf{A})$. The bone marrow is collected for bone marrow transplantation (B). The material collected is taken to the cell therapy laboratory for stem cell separation (C). Stem cells are injected into the patient's eye in an operating room (D). The patient is again evaluated at the research center (A).

Generally, the first phase of research explores what is needed in order to treat a disease so that potential treatments can be developed from basic laboratory research and to test the safety and efficacy of the medicines developed. The concepts involved in this phase form the basis of evidence-based practice and the creation of clinical guidelines. In relation to drug development, the term "from the bench to bedside" is properly employed. Many pharmaceutical companies have created teams of professionals to work with translational medicine so that the interaction between basic research and clinical medicine is facilitated, particularly for clinical trials. This is already occurring with the development of biological products specifically designed for autoimmune diseases. Thus, these days, the evaluation of therapies involves such diverse areas as psychology, physical therapy, and nutrition. The second phase of studies examines discoveries in clinical sciences and evaluates the effectiveness and safety of interventions. Hence, Phase 1 studies are transferred to practical applications in real life environments and dayto-day situations when different demographic factors and priorities can change clinical decisions and responses to treatment. Research in this phase plays a very informative role by providing information on the needs, acceptability, efficacy, and cost-effectiveness for the creation of health care policies that promote good management and use of resources. Particularly in the modern world in major economic recession, these needs should challenge the environment created by the restricted view often seen in the setting of clinical trials..$^{2,3}$
Phase III of translational research adds information necessary to convert treatment and preventive strategies, which have proven their effectiveness and cost-effectiveness in Phase 2, as the basis of more stringent, albeit more extensive and evidence-based government policies. These policies require different research processes to evaluate settings with more complex interactions. They involve a process of sustainability that relies on approaches that require continuous refinement and methodological improvements.

As a consequence, research and translational medicine have personalized medicine.

Personalized medicine, as a term, evolved to indicate that the results of various forms of genomic analysis are applied to tailor medical care for a specific patient with obvious advantages that supplement, but do not replace, traditional clinical medicine. These advantages include the possibility of predicting susceptibility for a disease and, as a result, allow more detailed screening or prophylactic (preventative) treatment. Personalized medicine also offers the potential for diagnosis of diseases at an early stage when treatment is often more effective and sequelae may be minimized. This is particularly true with respect to cancer. Potential beneficiaries of these novel technologies will primarily be our patients but medical care institutions will also benefit. There are vast business opportunities for companies that develop diagnoses, drugs, or methods for data analysis. Already several medical schools have developed institutes, programs, or curricula focused on personalized medicine. Companies have been formed employing marketing analysis that purports to predict one's risk of developing a myriad of diseases ranging from Alzheimer's disease and diabetes to baldness in men. ${ }^{2-5}$

Translational medicine has also had a great impact in ophthalmology. Some examples of research using this concept that will certainly be part of our everyday clinical practice in the near future are listed below.

\section{Genetic testing and gene therapy in retinal diseases}

The era of molecular ophthalmology began in 1985 with the discovery of the retinoblastoma gene. ${ }^{6}$ Since then, hundreds of other genes responsible for a variety of important diseases have been discovered, including genes associated with agerelated macular degeneration (AMD), glaucoma, congenital cataract, both syndromic and non-syndromic forms of photoreceptor degeneration, multiple macular dystrophies, corneal dystrophies, vitreoretinopathies, and optic neuropathies. The discovery of genetic causes of diseases allows individualized molecular investigations of DNA samples to be used 
in clinical diagnosis and prognosis and in counseling. In addition, individuals who are found to carry known diseasecausing mutations can be enrolled in clinical trials of new therapies or carefully studied to fully explore the behavior of their disease over time. ${ }^{7,8}$ Samples from patients who lack mutations of known disease-causing genes can also serve as a valuable resource for scientists who seek to find additional disease-causing genes. ${ }^{9}$

Experiments to discover genes implicated in different diseases have aided this research by providing an improved understanding of specific biologic pathways that, when out of balance, lead to disease or susceptibility for disease. Such pathways can become important targets for therapeutic agents and scientists have been very creative in devising treatment specifically aimed at these targets. ${ }^{9}$

For example, the discovery that the $A B C A 4$ gene is involved in transporting vitamin A derivatives from outer segment disks led to the discovery that vitamin A inhibitors, such as fenretinide, inhibit the accumulation of lipofuscin in animal models of Stargardt's disease. ${ }^{10,11}$ The identification of the role of vascular endothelial growth factor in choroidal neovascularization led to the development of therapeutic antibodies (eg, ranibizumab and bevacizumab) to combat the main blinding complications of AMD. Growth factors and neuroprotective agents have also been used to reduce the rate of apoptotic response to inherited cellular abnormalities. ${ }^{12,13}$ In recent years, gene-replacement therapy, therapeutic stem cells, and retinal prostheses have changed our approach to the treatment of genetic eye diseases.

More than a dozen recessive retinal diseases have been successfully treated with viral- or nanoparticle-based gene transfer in animal models. ${ }^{14}$ For example, one molecular form of Leber's congenital amaurosis is caused by the lack of retinoid isomerase encoded by the RPE65 gene and vision was restored in a naturally occurring canine model of this disease using an adeno-associated viral vector to transfer a normal version of RPE65 to the retinal pigment epithelium. ${ }^{15}$ More recently, three different groups have extended this work to humans. ${ }^{16-18}$ Maguire and colleagues reported results in twelve patients who were treated with gene-replacement therapy. They observed visual improvement in all twelve patients, with the greatest gains among younger patients. ${ }^{16}$

AMD is one of the best examples of a chronic degenerative genetic disease discovered to date; the hereditary factor is responsible for over $70 \%$ of the risk of developing the disease. Genetic testing can identify individuals with an increased risk for advanced AMD. ${ }^{19}$ Early identification of at-risk patients may prevent vision loss or slow the progression of the disease through individualized treatment based on age and risk level. Frequent monitoring of individuals with an increased risk for advanced AMD may result in early detection of small choroidal neovascularization lesions and may lead to improved long-term visual acuity through early treatment. Additionally, environmental risk factors can be identified and modifications in lifestyle can be made to reduce the risk of developing advanced AMD. ${ }^{20}$

Both the candidate gene approach and genome-wide association studies (GWAS) have been used to elucidate sequence variations associated with AMD. ${ }^{21}$ Early work identified the potential importance of the complement family of inflammatory proteins in AMD on the basis of biochemical analysis of retinal drusen. As the genes and naturally occurring sites of variability for all complement cascade proteins became known, statistically significant associations with neovascular AMD were identified. To date, convincing and reproducible associations of variations of the complement factor $\mathrm{H}(\mathrm{CFH})$, complement factor I $(\mathrm{CFI})$, complement factor $\mathrm{B}(\mathrm{CFB})$, and complement component (CC3) genes have been demonstrated. ${ }^{22-25}$

Macula Risk (ArcticDx, Inc, Toronto, ON) is a commercially available prognostic genetic test for patients diagnosed with early or intermediate AMD. Using an algorithm based on the complete combination of known AMD genes and history of smoking, the genetic test identifies those most likely to progress to advanced AMD with vision loss. Tested patients are stratified into risk categories; $20 \%$ of patients are predicted to have a higher than average lifetime risk of advanced AMD with $1 \%$ of those falling into a high-risk group with a predicted $65 \%$ chance of developing geographic atrophy or choroidal neovascularization. The ability to identify atrisk patients allows physicians to tailor a more appropriate management plan for individual patients. ${ }^{20}$

\section{Stem cell therapy in retinal diseases}

Several important cell types in the eye have little if any capacity for endogenous regeneration and as a result the only viable treatment option for patients with hereditary disorders that involve the loss of such cells is some type of cell replacement therapy. Although the replacement of highly differentiated cells, such as photoreceptors, poses challenges, a number of recent experiments suggest that the use of stem cells to achieve such a goal is now feasible. ${ }^{9}$

Distinct stem cell types have been established from embryos and identified in fetal tissues and umbilical cord blood as well as in specific niches in many adult mammalian 
tissues and organs such as bone marrow, brain, skin, eyes, heart, kidneys, lungs, gastrointestinal tract, pancreas, liver, breast, ovaries, and prostate. ${ }^{26}$

Stem cell-based therapy has been tested in animal models for several diseases, including neurodegenerative disorders, such as Parkinson disease, spinal cord injury, and multiple sclerosis. Replacing lost neurons which have not been physiologically replaced is pivotal to therapeutic success. In the eye, degeneration of neural cells in the retina is a hallmark of such widespread ocular diseases as AMD and retinitis pigmentosa (RP). In these cases the loss of photoreceptors that occurs as a primary event (as in RP) or secondary to loss of retinal-pigment epithelium (in AMD) leads to blindness. ${ }^{26-28}$

Stem cells can potentially be used for both neuroprotection and cell replacement. Intravitreal delivery of neurotrophic factors slows down photoreceptor degeneration in rodent models of RP and retinal ganglion cell loss in glaucoma models and optic nerve and optic tract trauma, but the effect may be temporary. Slow-release preparations and gene therapy approaches to induce retinal cells to secrete neurotrophic factors are two ways to induce longer-term effects. A third option is to use stem cells as long-term delivery agents, possibly encapsulated in a device because many stem cells either secrete neurotrophins naturally or can be genetically engineered to do so. .9,30 $^{29}$

Recently, some reports demonstrated the clinical feasibility of the intravitreal administration of autologous bone marrow-derived mononuclear cells in patients with advanced degenerative retinopathies. ${ }^{31,32}$ More recently, our group conducted a prospective Phase I trial to investigate the safety of intravitreal bone marrow-derived mononuclear cells in patients with retinitis pigmentosa or cone-rod dystrophy, with promising results. ${ }^{33}$

In 2010, the US Food and Drug Administration granted Orphan Drug designation for RPE cells of Advanced Cell Technology, Inc to initiate its Phase I/II clinical trials using retinal pigment epithelial cells derived from human embryonic stem cells to treat patients with Stargardt's Macular Dystrophy and in 2011 the company received a positive opinion from the Committee for Orphan Medicinal Products of the European Medicines Agency towards designation of this product as an orphan medicinal product for the treatment of Stargardt's disease. ${ }^{34}$

Stem cells maintain the balance between somatic cell populations in several tissues and are responsible for organ regeneration. The remarkable progress of regenerative medicine over the last few years is promising for the use of stem cells in the treatment of ophthalmic disorders. Based on this success, experimental and human studies of bone marrowderived stem cells have begun.

Research using stem cells opened another arm in translational research.

The need to use the lab, biologists, and clinical experts has created a multidisciplinary environment, which is a characteristic of translational medicine.

\section{Retinal prosthesis technology}

Retinal prosthesis technology is currently under development in more than 13 centers across five continents worldwide, although the technology used, and stages of development in the various groups, differ significantly.

Extensive efforts have been undertaken to develop artificial devices aimed at restoring some vision in blind individuals. Most of these devices use electrical currents to stimulate the visual pathway, thereby bypassing damaged structures. ${ }^{35-41}$ Briefly, these devices incorporate an image capture module (eg, a camera), a processor that transforms the captured image into a pattern of stimulating currents and an electrode array through which electrical currents are delivered to the target stimulation site (retina, optic nerve, or visual cortex). Among these, retinal prostheses are probably the most advanced as the first clinical trials are currently underway. ${ }^{36}$ Patients with advanced retinal degenerative diseases and their family members often actively seek information on the latest neuroprotective treatments aimed at slowing down the progression of their disease or rehabilitative technologies that may restore their sight. Retina physicians are faced with the task of explaining to patients the state of retinal prosthesis technology, including when it will become practical and what level of vision might be restored. While this may seem daunting, a systematic approach to categorizing retinal prosthesis technology greatly simplifies comprehension of this field.

A retinal prosthesis is a device that gathers visual information with an electronic detector, then processes and converts that image into a form of stimulation that the retina and brain can interpret as a form of vision. All retinal prostheses can be categorized according to three fundamental design features - detector type, stimulation type, and stimulation site.

Detectors for retinal prostheses can be complementary metal-oxide-semiconductor (CMOS) or charge-coupled device (CCD) chips found in webcams or camcorders to microphotodiodes that act as tiny solar cells, turning light directly into electrical current. ${ }^{36-41}$ 
Most retinal prostheses under development today employ electrical current to stimulate the retina, producing electrophosphenes. These are small, round, oval, or elongated spots of light produced when pulses of electrical current are applied to the retina. ${ }^{41}$

In an effort to develop a more naturalistic method of retinal stimulation, the collaborative groups at Wayne State University and Mayo Clinic are designing methods to deliver neurotransmitters to retinal neurons using microfluidic technology. This approach leverages natural chemical visual channels within the retina and can stimulate or inhibit neuronal firing, thus forming the basis for visual contrast. This technique employs the controlled delivery of neurotransmitters to the retina in space and time, analogous to the way an inkjet printer puffs ink onto paper. ${ }^{41,42}$

The most critical component of the retinal prosthesis system is the tissue interface formed at the junction of the neurosensory retina and the stimulator.

Subretinal placement assures close proximity to the neurosensory retina and obviates the need for tack fixation as the retina is draped over the stimulation sites. However the surgical approach is more complex as it requires a pars plana vitrectomy, formation of a localized retinal detachment bleb and trans-scleral, trans-choroidal incisions for the ab-externo insertion of the stimulator into the subretinal space. After insertion, the retina is re-attached via internal tamponade..$^{38,40}$

Retinal prosthesis technology has been under development for more than two decades. Several different designs for retinal prostheses have had promising results in both animals and humans and one of these designs has recently been approved for clinical use in Europe. ${ }^{41,42}$

The junction of the fields of bioengineering, biomaterials, neurology, and ophthalmology has allowed translational research to develop a system of intraocular retinal prosthesis.

\section{Conclusion}

Translational medicine has been described as the integrated application of innovative pharmacology tools, biomarkers, clinical methods, clinical technologies, and study designs to improve the understanding of medical disorders. In medicine, translational research offers an opportunity to apply the findings obtained in basic research to everyday clinical applications.

Translational medicine is the development of more useful methods that allow a better application of basic researchbased knowledge to the medical field as we are now seeing in the area of ophthalmology.

\section{Disclosure}

The authors report no conflicts of interest in this work.

\section{References}

1. Franco de Oliveira LV. From bench to bedside. ConScientiae Saúde. 2009;8:545-547.

2. Lean MEJ, Mann JI, Hoek JA, Elliot RM, Schofield G. Translational Research: from evidence-based medicine to sustainable solutions for public health problems. Br Med J. 2008;337:a863.

3. Hiss RG. Fundamental issues in translational research. Translational research - two phases of a continuum. From clinical trials to community: the science of translating diabetes and obesity research. Natcher Conference Center, National Institutes of Health, Bethesda, MD. Available at: http:// www2.niddk.nih.gov/Research/Reports/ConferenceReports/2004/ diabetes_translation.htm. Accessed on October 4, 2011. 2004:11-14.

4. Demeure MJ. Personalized medicine: the future is not what it used to be. Surgery. 2009;146:971-978.

5. Hamburg MA, Collins FS. The path to personalized medicine. $N$ Engl J Med. 2010;363:301-304.

6. Swaroop A, Chew EY, Rickman CB, Abecasis GR. Unraveling a multifactorial late-onset disease: from genetic susceptibility to disease mechanisms for age-related macular degeneration. Annu Rev Genomics Hum Genet. 2009;10:19-43.

7. Schindler EI, Nylen EL, Ko AC, et al. Deducing the pathogenic contribution of recessive ABCA4 alleles in an outbred population. Hum Mol Genet. 2010;19:3693-3701.

8. Cideciyan AV, Swider M, Aleman TS, et al. ABCA4 disease progression and a proposed strategy for gene therapy. Hum Mol Genet. 2009;18:931-941.

9. Sheffield VC, Stone EM. Genomics and the eye. N Engl J Med. 2011; 364:1932-1942.

10. Weng J, Mata NL, Azarian SM, Tzekov RT, Birch DG, Travis GH. Insights into the function of Rim protein in photoreceptors and etiology of Stargardt's disease from the phenotype in abcr knockout mice. Cell. 1999;98:13-23.

11. Radu RA, Han Y, Bui TV, et al. Reductions in serum vitamin A arrest accumulation of toxic retinal fluorophores: a potential therapy for treatment of lipofuscin-based retinal diseases. Invest Ophthalmol Vis Sci. 2005;46: 4393-4401. [Erratum, Invest Ophthalmol Vis Sci. 2006;47:3735.]

12. Sieving PA, Caruso RC, Tao W, et al. Ciliary neurotrophic factor (CNTF) for human retinal degeneration: phase I trial of CNTF delivered by encapsulated cell intraocular implants. Proc Natl Acad Sci U S A. 2006;103:3896-3901.

13. Boatright JH, Moring AG, McElroy C, et al. Tool from ancient pharmacopoeia prevents vision loss. Mol Vis. 2006;12:1706-1714.

14. den Hollander AI, Black A, Bennett J, Cremers FP. Lighting a candle in the dark: advances in genetics and gene therapy of recessive retinal dystrophies. J Clin Invest. September 1, 2010;120(9):3042-3053. [Erratum, J Clin Invest. 2011;121:456-457.]

15. Acland GM, Aguirre GD, Ray J, et al. Gene therapy restores vision in a canine model of childhood blindness. Nat Genet. 2001;28:92-95.

16. Maguire AM, Simonelli F, Pierce EA, et al. Safety and efficacy of gene transfer for Leber's congenital amaurosis. $N$ Engl J Med. 2008;358:2240-2248.

17. Bainbridge JW, Smith AJ, Barker SS, et al. Effect of gene therapy on visual function in Leber's congenital amaurosis. $N$ Engl J Med. 2008;358:2231-2239.

18. Hauswirth WW, Aleman TS, Kaushal S, et al. Treatment of Leber congenital amaurosis due to RPE65 mutations by ocular subretinal injection of adeno-associated virus gene vector: short-term results of a phase I trial. Hum Gene Ther. 2008;19:979-990.

19. Chen W, Stambolian D, Edwards AO, et al. Genetic variants near TIMP3 and high-density lipoprotein-associated loci influence susceptibility to age-related macular degeneration. Proc Natl Acad Sci US A. 2010;107:7401-7406. 
20. Awh CC, Zanke B. Applying genetic risk data to clinical practice. Retina Today. 2011:78-79.

21. Haines JL, Spencer KM, Pericak-Vance MA. Bringing the genetics of macular degeneration into focus. Proc Natl Acad Sci USA. 2007;104:16725-16726.

22. Klein RJ, Zeiss C, Chew EY, et al. Complement factor H polymorphism in age-related macular degeneration. Science. 2005;308:385-389.

23. Fagerness JA, Maller JB, Neale BM, Reynolds RC, Daly MJ, Seddon JM. Variation near complement factor I is associated with risk of advanced AMD. Eur J Hum Genet. 2009;17:100-104.

24. Yates JR, Sepp T, Matharu BK, et al. Complement C3 variant and the risk of age-related macular degeneration. $N$ Engl J Med. 2007;357:553-561.

25. Jakobsdottir J, Conley YP, Weeks DE, Ferrell RE, Gorin MB. C2 and CFB genes in age-related maculopathy and joint action with $\mathrm{CFH}$ and LOC387715 genes. PLoS ONE. 2008;3:2199.

26. Siqueira RC, Voltarelli JC, Messias AM, Jorge R. Possible mechanisms of retinal function recovery with the use of cell therapy with bone marrow-derived stem cells. Arq Bras Oftalmol. 2010;73:474-479.

27. Lanza R, Rosenthal N. The stem cell challenge. Sci Am. 2004;290: 93-99.

28. Machaliñski A, Baumert B, Kuprjanowicz L, Wiszniewska B, Karczewicz D, Machaliñski B. Potential application of adult stem cells in retinal repair-challenge for regenerative medicine. Curr Eye Res. 2009;34:748-760.

29. Otani A, Dorrell MI, Kinder K, et al. Rescue of retinal degeneration by intravitreally injected adult bone marrow-derived lineage negative hematopoietic stem cells. J Clin Invest. 2004;114:765-774. Comment in: J Clin Invest. 2004;114:755-757.

30. Dahlmann-Noor A, Vijay S, Jayaram H, Limb A, Khaw PT. Current approaches and future prospects for stem cell rescue and regeneration of the retina and optic nerve. Can J Ophthalmol. 2010;45:333-341.

31. Jonas JB, Witzens-Harig M, Arseniev L, Ho AD. Intravitreal autologous bone marrow derived mononuclear cell transplantation: a feasibility report. Acta Ophthalmol. 2008;86:225-226.
32. Jonas JB, Witzens-Harig M, Arseniev L, Ho AD. Intravitreal autologous bone marrow-derived mononuclear cell transplantation. Acta Ophthalmol. 2010;88:131-132.

33. Siqueira RC, Messias A, Voltarelli JC, Scott IU, Jorge R. Intravitreal injection of autologous bone marrow-derived mononuclear cells for hereditary retinal dystrophy: a phase I trial. Retina. 2011; 31:1207-1214.

34. Schwartz S. Sub-retinal Transplantation of hESC Derived RPE (MA09-hRPE) Cells in Patients with Stargardt's Macular Dystrophy. NCT01345006. Clinicaltrials.gov.

35. Dowling J. Current and future prospects for optoelectronic retinal prostheses. Eye (Lond). 2009;23:1999-2005.

36. Ong JM, Cruz LD. The bionic eye: a review. Clin Exp Ophthalmol. 2011. [Epub ahead of print.]

37. Humayun MS, Dorn JD, Ahuja AK, et al. Preliminary 6 month results from the Argus II epiretinal prosthesis feasibility study. Conf Proc IEEE Eng Med Biol Soc. 2009;2009:4566-4568.

38. Gekeler F, Kopp A, Sachs H, et al. Visualisation of active subretinal implants with external connections by high-resolution CT. $\mathrm{Br} J$ Ophthalmol. 2010;94:843-847.

39. Petermeier K, Frank C, Gekeler F, Spitzer MS, Messias A, Szurman P. Influence of the pupil size on visual quality and spherical aberration after implantation of the Tecnis 1-piece intraocular lens. Br J Ophthalmol. 2011;95:42-45.

40. Besch D, Sachs H, Szurman P, et al. Extraocular surgery for implantation of an active subretinal visual prosthesis with external connections: feasibility and outcome in seven patients. $\mathrm{Br} J$ Ophthalmol. 2008;92:1361-1368.

41. Chader G, Weiland J, Humayun M. Artificial vision: needs, functioning, and testing of a retinal electronic prosthesis. Prog Brain Res. 2009; 175:317-332.

42. Finlayson P, Iezzi R. Glutamate stimulation of retinal ganglion cells in normal and s334ter rat retinas: a candidate for a neurotransmitterbased retinal prosthesis. Invest Ophthalmol Vis Sci. 2010;51: 3619-3628.
Clinical Ophthalmology

\section{Publish your work in this journal}

Clinical Ophthalmology is an international, peer-reviewed journal covering all subspecialties within ophthalmology. Key topics include: Optometry; Visual science; Pharmacology and drug therapy in eye diseases; Basic Sciences; Primary and Secondary eye care; Patient Safety and Quality of Care Improvements. This journal is indexed on Submit your manuscript here: http://www.dovepress.com/clinical-ophthalmology-journal

\section{Dovepress}

PubMed Central and CAS, and is the official journal of The Society of Clinical Ophthalmology (SCO). The manuscript management system is completely online and includes a very quick and fair peer-review system, which is all easy to use. Visit http://www.dovepress.com/ testimonials.php to read real quotes from published authors. 